\title{
Reproductive characteristics of the lobate ctenophore Bolinopsis mikado (Moser)
}

\author{
TOMOYUKI KASUYA $^{1,2 *}$, TAKASHI ISHIMARU ${ }^{1} \&$ MASAAKI MURANO $^{1,3}$ \\ ${ }^{1}$ Department of Ocean Sciences, Tokyo University of Fisheries (present name: Tokyo University of Marine Science and \\ Technology), 4-5-7 Konan, Minato-ku, Tokyo 108-8477, Japan \\ ${ }^{2}$ Present address: Nagasaki Prefectual Institute for Environmental Research and Public Health, 2-1306-11 Ikeda Omura-shi, \\ Nagasaki 856-0026, Japan \\ ${ }^{3}$ Present address: 3-32-36, Shimo-Takaido, Suginami-ku, Tokyo 168-0073, Japan
}

Received 18 December 2006; Accepted 14 December 2007

\begin{abstract}
The egg production rate (EPR) of the lobate ctenophore Bolinopsis mikado was measured in summer, fall, and winter using field-collected animals whose total lengths (TL) ranged from $17 \mathrm{~mm}$ to $73 \mathrm{~mm}$. The TL of spawning $B$. mikado ranged from $22 \mathrm{~mm}$ to $73 \mathrm{~mm}$, indicating that B. mikado matures at ca. $20 \mathrm{~mm}$ TL. Because the percentage of spawning individuals to the total ranged from $50 \%$ to $100 \%$, B. mikado probably spawned intermittently or daily in Tokyo Bay. Spawning individuals were found even in December and January. Bolinopsis mikado seemed to reproduce continuously in Tokyo Bay throughout the year. A multiple regression analysis between the EPR and ctenophore body size and water temperature suggested that $21.5 \%$ of EPR can be explained by these variables. The EPR increased linearly with ctenophore size, i.e. the wet-weight specific EPR (EPR*) was independent of the body size. The relationship between the EPR* and water temperature was equivalent to a $Q_{10}$ value of 4.7, and was considerably higher than that of the respiration, predation, and growth rates, which may lead to quick population growth and mass occurrence of $B$. mikado during summer and fall in coastal waters.
\end{abstract}

Key words: Bolinopsis, ctenophores, larvae, reproduction, Tokyo Bay

\section{Introduction}

Ctenophores are voracious predators that significantly affect mesozooplankton and fish egg/larva biomasses (Deason 1982, Purcell \& Arai 2001). Recently, neritic and estuarine ctenophores were accidentally introduced into eutrophicated waters in various parts of the world, possibly through ship ballast water, and the outbreak has become a major problem in the Black Sea, the Sea of Azov, and elsewhere (Zaitsev 1992, Purcell et al. 2001). Drastic population growth and mass occurrences of ctenophores have been reported by many researchers (Deason \& Smayda 1982, Kremer 1994, Mutlu et al. 1994, Kasuya et al. 2000a, Sullivan et al. 2001) and indicate that ctenophores have high growth and reproductive capabilities (Kremer \& Reeve 1989). Since most ctenophores are too fragile to be preserved in formalin or in any preservative presently known, it is difficult to determine the egg production rate by count-

\footnotetext{
*Corresponding author: Tomoyuki Kasuya; E-mail: kasuya@pref.
} nagasaki.lg.jp ing eggs in ovaries of preserved specimens collected from the field. Nevertheless, some quantitative information on the reproduction of ctenophores has been obtained from field and laboratory experiments. Such studies on ctenophore egg production have been conducted on the lobate species Mnemiopsis leidyi A. Agassiz (Kremer 1975), Mnemiopsis mccradyi Mayer (Baker \& Reeve 1974, Reeve et al. 1989), and Ocyropsis crystallina guttata (Rang) (Harbison \& Miller 1986), and the cydippids Pleurobrachia pileus Vanhöffen (Greve 1970) and Pleurobrachia bachei A. Agassiz (Hirota 1972, 1974). Greve (1970) reported on the reproduction of the beroid ctenophore Beroe gracilis Künne.

In Japanese coastal waters, Bolinopsis mikado (Moser) is the predominant ctenophore species (Komai 1915, Kanashiro \& Senta 1985) and is most abundant from late summer to mid-fall in Tokyo Bay (Kasuya et al. 2000a). Some ecological studies on the abundance, feeding, metabolism, and growth of B. mikado have been reported (Kasuya et al. 1994, 2000a, b, 2002), but its reproduction rate has not been determined. In the present paper, the egg produc- 
tion rate of B. mikado was determined from summer through winter using field-collected animals of various sizes. The elemental composition (carbon and nitrogen) of the eggs was also determined.

\section{Materials and Methods}

\section{Preliminary experiment}

A series of experiments was conducted from July to October 1994, from July to December 1995, and in January 1996 at the Banda Marine Laboratory of Tokyo University of Fisheries (present name: Tokyo University of Marine Science and Technology), Tateyama, Chiba Prefecture, which is located near the mouth of Tokyo Bay $\left(34^{\circ} 58^{\prime} 30^{\prime \prime} \mathrm{N}\right.$, $139^{\circ} 46^{\prime} 12^{\prime \prime} \mathrm{E}$ ).

A preliminary experiment was conducted on August and October in 1994 to examine the effect of the volume of seawater in a bottle on the egg production rate (EPR, eggs ctenophore $\left.{ }^{-1} \mathrm{~d}^{-1}\right)$ of Bolinopsis mikado. Four animals with total lengths (TL, Fig. 1) of 50, 51, 55, and $59 \mathrm{~mm}$ were incubated in 2-liter bottles containing 1 liter of seawater, and three animals of 54,54 , and $55 \mathrm{~mm}$ TL were incubated in 2liter bottles containing 1.5 liters of seawater at water temperatures ranging from 23.1 to $26.9^{\circ} \mathrm{C}$. The sampling method of B. mikado and procedure of the experiment were the same as those in "Measurement of egg production rate" as described below.

For measurement of the carbon and nitrogen contents of the eggs, the eggs of $B$. mikado remaining in the bottles were pipetted into a petri dish and rinsed with filtered seawater (Whatman $\mathrm{GF} / \mathrm{C}$ filter). After replicating the above procedure, various numbers of eggs were rinsed with $5 \%$ isotonic ammonium formate to remove seawater and gently filtered through a precombusted Whatman GF/C filter $\left(400^{\circ} \mathrm{C}\right.$ for $\left.3 \mathrm{~h}\right)$. A count of the eggs on the filter using a dissecting microscope provided four samples of eggs containing 15, 19, 39, and 52 eggs, respectively. The samples were dried at $90^{\circ} \mathrm{C}$ for $2 \mathrm{~d}$, and the carbon and nitrogen contents of each were measured by a CHN Corder (MT-3, Yanaco Co. Ltd., Kyoto, Japan).

\section{Measurement of egg production rate}

Samples of B. mikado were collected using widemouthed plastic bottles by snorkeling in waters adjacent to the laboratory. In the experiment, 59 specimens, ranging from 17 to $73 \mathrm{~mm}$ TL, were used to determine the EPR. Immediately after collection, the TL of each B. mikado specimen was measured to the nearest $1 \mathrm{~mm}$ using calipers, after which the specimen was transferred into a cylindrical glass bottle containing seawater $(0.5,1.0$, and 1.5 liters). The size of the bottle and the volume of seawater in it depended on the ctenophore body size. A 1-liter bottle containing 0.5 liters of filtered seawater was used to incubate individuals of $<30 \mathrm{~mm} \mathrm{TL}$, and a 2-liter bottle containing 1.0 or 1.5 liters of filtered seawater was used for individuals ranging
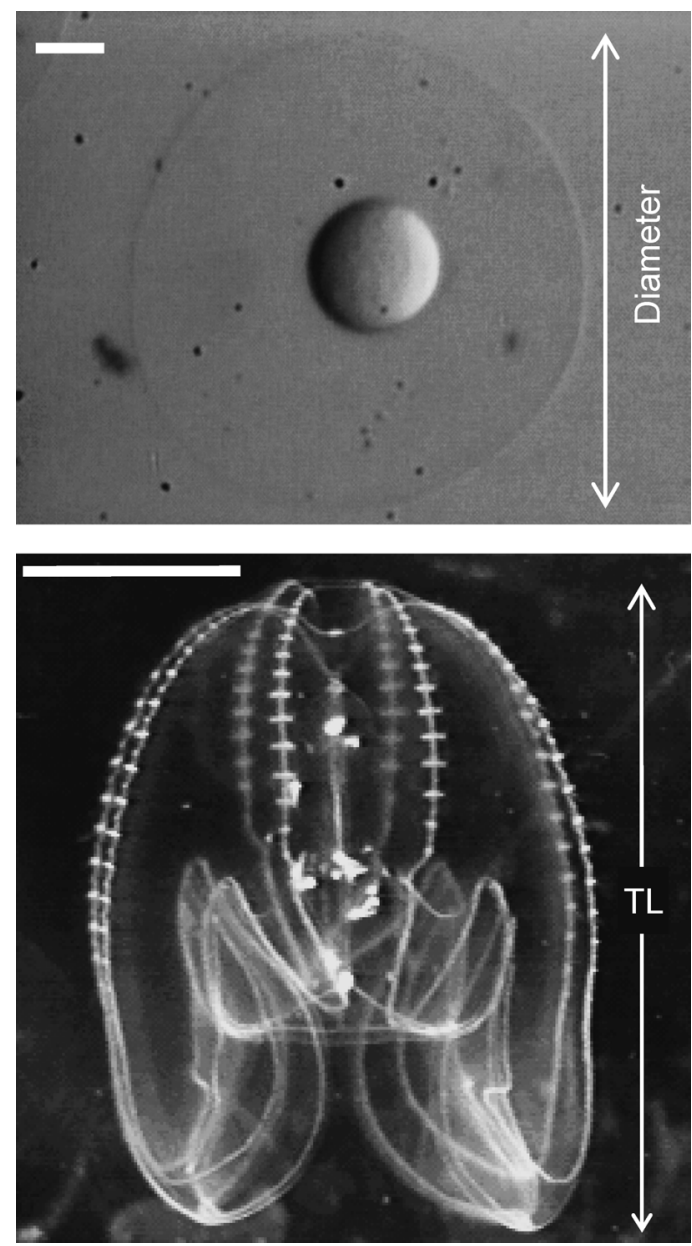

Fig. 1. Photographs of an egg (upper) and a post-larva (lower) of Bolinopsis mikado. The double-arrowhead lines in the photographs represent measurements of the diameter of eggs and total length (TL) of the post-larva. The scale bar represents $0.1 \mathrm{~mm}$ for the egg and $5 \mathrm{~mm}$ for the post-larva.

from 30 to $60 \mathrm{~mm}$ TL or $>60 \mathrm{~mm}$ TL. The seawater, pumped up from waters adjacent to the laboratory, was first sand filtered, then further filtered using a Whatman GF/C filter. The bottles were kept in a water bath of running sandfiltered seawater for $24 \mathrm{~h}$ under a 12 light : 12 dark light cycle. The water temperature of the sand-filtered seawater was determined every hour using a telemetry buoy (SEACOM, Sanyo Techno Marine Inc., Tokyo, Japan). The daily fluctuation of the water temperature during the experiments was at maximum $2.3^{\circ} \mathrm{C}$ (see Table 3). Therefore, in this paper, we employed the mean water temperature as the experimental temperature.

The released eggs sank and accumulated on the bottom of the bottle. Thus, at the end of the incubation period, $B$. mikado was removed, the seawater in the bottle was mixed well, the subsample was collected in a measuring cylinder in $200 \mathrm{~mL}$ of the seawater, and the number of eggs was counted under a dissecting microscope. The eggs of $B$. mikado are spherical and enclosed in a gelatin capsule (Fig. 
1), approximately $0.7 \mathrm{~mm}$ in diameter including the capsule. Since many ctenophores are capable of self-fertilization (e.g. Baker \& Reeve 1974), hatched larvae of $B$. mikado were also observed in the bottle. Thus, we counted the hatched larvae and eggs.

\section{Results}

\section{Effect of container size on reproduction}

The TL of Bolinopsis mikado was converted to the wet weight (WW, g) using an equation: $\mathrm{WW}=0.0005 \mathrm{TL}^{2.72}$ (Kasuya et al. 1994), and the WW-specific EPR (EPR*, eggs $\mathrm{g} \mathrm{WW}^{-1} \mathrm{~d}^{-1}$ ) was obtained. Four specimens, with TLs ranging from $50-59 \mathrm{~mm}$, incubated in 1.0 liter of seawater, spawned 6-100 eggs $\mathrm{g} \mathrm{WW}^{-1} \mathrm{~d}^{-1}$ with a mean of $48 \pm 38$. Three specimens with TLs ranging from $54-55 \mathrm{~mm}$, incubated in 1.5 liters of seawater, spawned 34-52 eggs $\mathrm{gWW}^{-1} \mathrm{~d}^{-1}$ with a mean of $42 \pm 9$. Assuming $1 \mathrm{~mL}$ of seawater equals $1 \mathrm{mg}$, the ratio of $B$. mikado WW to the volume of seawater was $\leq 1: 30$, and no significant differences were observed between the reproduction rate in 1.0 liter and that in 1.5 liters of seawater ( $t$-test, $p=0.38$ ).

\section{Egg production rate}

The relationships between the number of eggs and their carbon $(\mathrm{C})$ and nitrogen $(\mathrm{N})$ contents were fitted to a linear regression equation, and significant slopes of 0.57 $\left(r^{2}=0.98, p=0.0078\right)$ for $\mathrm{C}$ and $0.15\left(r^{2}=0.97, p=0.016\right)$ for $\mathrm{N}$ were obtained. Thus, the carbon and nitrogen weights in an individual egg were $0.57 \mu \mathrm{g}$ and $0.15 \mu \mathrm{g}$, respectively.

The TL of the spawning B. mikado ranged from $22 \mathrm{~mm}$ to $73 \mathrm{~mm}$. The minimum TL for a spawning individual was observed in August 1994, and its EPR was 10 eggs ctenophore ${ }^{-1} \mathrm{~d}^{-1}$. The maximum EPR was 2550 eggs ctenophore ${ }^{-1} \mathrm{~d}^{-1}$ obtained from an individual of

Table 1. Ratio of spawning individuals to the total number of Bolinopsis mikado individuals with a total length (TL) exceeding $20 \mathrm{~mm}$.

\begin{tabular}{lccc}
\hline Date & $\begin{array}{c}\text { Range of } \\
\text { TL (mm) }\end{array}$ & $n$ & $\begin{array}{c}\text { \% of spawning } \\
\text { individuals }\end{array}$ \\
\hline 1994 & & & \\
9 Jul. & $21-64$ & 18 & 56 \\
24-26 Aug. & $20-65$ & 26 & 85 \\
4 Oct. & $30-59$ & 7 & 100 \\
1995 & & & \\
19 Jul. & $44-62$ & 5 & 100 \\
12 Aug. & $39-53$ & 4 & 50 \\
14 Oct. & $52-58$ & 4 & 75 \\
13 Nov. & $58-68$ & 5 & 100 \\
13, 17 Dec. & $62-65$ & 2 & 100 \\
1996 & & & \\
24, 28 Jan. & $57-74$ & 4 & 50 \\
\hline
\end{tabular}

$65 \mathrm{~mm}$ TL. Assuming the body carbon of B. mikado to be $1.10 \%$ of the dry weight (DW), the TL was converted to body carbon content using the equations: $\mathrm{DW}=0.062 \mathrm{TL}^{2.34}$ (Kasuya et al. 2000b). Thus, the EPR by $22 \mathrm{~mm}$ TL and $65 \mathrm{~mm}$ TL B. mikado mentioned above equals $6.0 \%$ and $13.5 \%$ of the individuals' body carbon, respectively.

The ratio of the number of spawning individuals to the total number of individuals was obtained using specimens exceeding a maturation size of $20 \mathrm{~mm}$ TL (see Discussion). The percentage of spawning individuals ranged from $50 \%$ to $100 \%$, and no seasonal pattern was found (Table 1).

\section{Multiple regression analysis of the egg production rate}

Using the data of the spawning B. mikado, a multiple regression analysis was performed between the EPR and ctenophore body size and water temperature $\left(\mathrm{T},{ }^{\circ} \mathrm{C}\right)$. Since B. mikado seems to mature at ca. $20 \mathrm{~mm}$ TL, i.e., $1.7 \mathrm{~g} \mathrm{WW}$, the variable of body size was given by WW -1.7 , and a significant multiple regression equation,

$$
E P R=33.77(W W-1.7)+119.05 T-2734.21,
$$

was obtained (Table 2). Coefficients of the variables WW-1.7 $(p=0.0001)$ and $\mathrm{T}(p=0.0024)$, and the y-inter-

Table 2. Multiple regression statistics of the relationship between the egg production rate (eggs ctenophore ${ }^{-1} \mathrm{~d}^{-1}$ ) of Bolinopsis mikado and body size (WW-1.7, g) and water temperature $\left(\mathrm{T},{ }^{\circ} \mathrm{C}\right)$.

\begin{tabular}{crcrc}
\hline Item & Coefficient & $\begin{array}{c}\text { Standard partial } \\
\text { regression } \\
\text { coefficient }\end{array}$ & $t$ & $p$ \\
\hline Variable & & & & \\
WW-1.7 & 33.77 & 0.616 & 4.169 & 0.0001 \\
T & 119.05 & 0.468 & 3.169 & 0.0024 \\
y-intercept & -2734.21 & & -2.745 & 0.0081 \\
\hline
\end{tabular}

$n=59$, adjusted $r^{2}=0.215, F=8.977, p=0.0004$

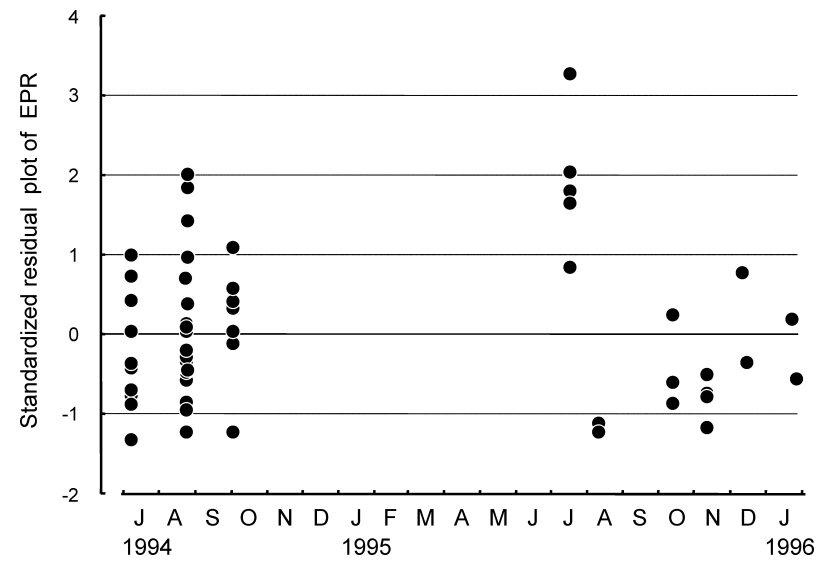

Fig. 2. Standardized residual plots of the egg production rate (EPR) of Bolinopsis mikado versus the experimental month. 
cept ( $p=0.0081$ ) were also significant. The standard partial regression coefficient was 0.616 for $\mathrm{WW}-1.7$ and 0.468 for water temperature. An adjusted $R^{2}$ of 0.215 is the proportion of variance explained by the regression equation, i.e., $21.5 \%$ of EPR was able to be explained by ctenophore body size and water temperature.

To examine outliers, an analysis of residuals was performed using the standardized residual (SR) of EPR plotted versus the experimental month. The highest SR value of 3.265 was obtained from July 1995, and all the SRs for this month were positive (Fig. 2). Although the SR in 1994 was distributed almost uniformly around the axis of zero, the SRs after July 1995 were mainly negative.

\section{Relationships of EPR to body size and water tempera- ture}

The relationship between the EPR and the ctenophore body size was expressed by an allometric equation EPR= $a(\mathrm{WW}-1.7)^{b}$, where $a$ and $b$ are constants (Table 3). A significant regression equation was found for the data obtained from July $\left(r^{2}=0.71, p=0.001\right)$ and August in 1994 $\left(r^{2}=0.71, p<0.000001\right)$. The constant $b$ of the significant regression equation was 2.54 for July 1994 and 1.20 for August 1994.

The effect of water temperature on the fecundity of $B$. mikado was evaluated by the EPR* (Fig. 3). The relationship between the EPR* and water temperature was expressed by an exponential equation, $\mathrm{EPR}^{*}=a e^{k \mathrm{~T}}$, where $a$ and $k$ are constants and $\mathrm{T}$ is the water temperature $\left({ }^{\circ} \mathrm{C}\right)$. Be- cause the EPR* obtained from July and August in 1995 seemed to have been strongly affected by food supply (see Discussion), these data were excluded from the regression analysis. We obtained a significant regression equation: $\mathrm{EPR}^{*}=0.75 e^{0.155 \mathrm{~T}}, r^{2}=0.67, p=0.024$. A coefficient $k$ of 0.155 was equivalent to a $Q_{10}$ value of 4.7.

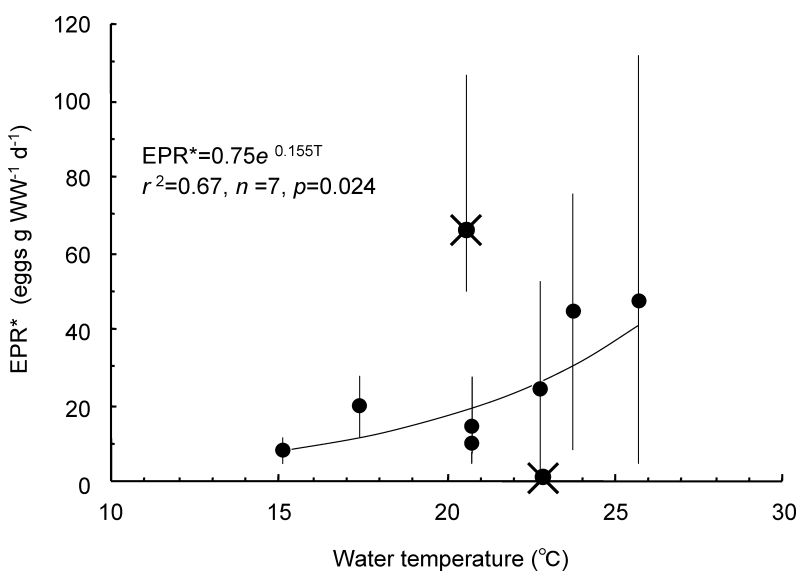

Fig. 3. Effect of water temperature on wet-weight-specific egg production rate (EPR*) of Bolinopsis mikado. Closed circles indicate the mean $\mathrm{EPR}^{*}$, and bars indicate the range of EPR* in each data set. Because the data with crosses (EPR*s obtained from July and August in 1995) appear to have been strongly affected by food supply, these data were excluded from the regression.

Table 3. Relationship between wet weight (WW, g) and egg production rate (EPR, eggs ctenophore ${ }^{-1} \mathrm{~d}^{-1}$ ) of Bolinopsis mikado at experimental water temperatures. Regression coefficients $a$ and $b$ were obtained from the regression equation, EPR $=a(\mathrm{WW}-1.7)^{b} . r^{2}$ represents the determination coefficient, and $n$ is the number of spawning individuals. CI is the $95 \%$ confidence interval for $b$. WW-specific EPR $\left(\mathrm{EPR}^{*}\right)$ at each experimental water temperature is also presented.

\begin{tabular}{|c|c|c|c|c|c|c|c|c|c|c|}
\hline \multirow{2}{*}{ Date } & \multicolumn{2}{|c|}{ Water temperature $\left({ }^{\circ} \mathrm{C}\right)$} & \multirow{2}{*}{$n$} & \multirow{2}{*}{$\begin{array}{l}\text { WW range } \\
(\mathrm{g})\end{array}$} & \multirow{2}{*}{$a$} & \multirow{2}{*}{$\begin{array}{c}b \\
(95 \% \mathrm{CI})\end{array}$} & \multirow{2}{*}{$r^{2}$} & \multirow[b]{2}{*}{$p$} & \multicolumn{2}{|c|}{$\mathrm{EPR}^{*}\left(\right.$ eggs g WW $\left.\mathrm{W}^{-1} \mathrm{~d}^{-1}\right)$} \\
\hline & Range & Mean & & & & & & & Range & Mean \\
\hline \multicolumn{11}{|l|}{1994} \\
\hline 9 Jul. & $22.2-23.5$ & 22.8 & 11 & $10.6-40.9$ & 0.12 & $\begin{array}{c}2.54 \\
(1.33-3.75)\end{array}$ & 0.71 & 0.001 & $2-52$ & 24 \\
\hline 24-26 Aug. & $24.6-26.9$ & 25.7 & 22 & $2.2-42.7$ & 26.5 & $\begin{array}{c}1.20 \\
(0.84-1.55)\end{array}$ & 0.71 & $<0.000001$ & $5-111$ & 47 \\
\hline 4 Oct. & $23.1-24.3$ & 23.8 & 7 & $5.2-32.8$ & 105.0 & $\begin{array}{c}0.64 \\
(-3.92-1.68)\end{array}$ & 0.34 & 0.17 & $8-75$ & 44 \\
\hline \multicolumn{11}{|l|}{1995} \\
\hline 19 Jul. & $21.0-21.6$ & 21.3 & 5 & $14.8-37.5$ & 88.8 & $\begin{array}{c}0.92 \\
(-0.42-2.26)\end{array}$ & 0.61 & 0.11 & $50-106$ & 66 \\
\hline 12 Aug. & $22.4-23.5$ & 22.9 & 2 & $22.1-24.5$ & - & - & - & - & $0.5-1.2$ & 0.8 \\
\hline 14 Oct. & $20.5-21.1$ & 20.8 & 3 & $24.5-31.3$ & $1.15 \times 10^{8}$ & $\begin{array}{c}-3.93 \\
(-34.7-26.8)\end{array}$ & 0.72 & 0.35 & $7-27$ & 14 \\
\hline 13 Nov. & $20.6-21.2$ & 20.8 & 5 & $31.3-48.2$ & 2.1 & $\begin{array}{c}1.43 \\
(-3.17-6.04)\end{array}$ & 0.24 & 0.39 & $4-14$ & 10 \\
\hline $\begin{array}{l}\text { 13, } 17 \text { Dec. } \\
1996\end{array}$ & $16.7-18.1$ & 17.4 & 2 & $37.5-42.7$ & - & - & - & - & $12-27$ & 19 \\
\hline 24, 28 Jan. & $14.7-15.6$ & 15.1 & 2 & $29.9-58.5$ & - & - & - & - & $4-11$ & 8 \\
\hline
\end{tabular}




\section{Discussion}

\section{Effect of container size on reproduction}

The fecundity of ctenophores may depend on experimental conditions such as container volume (e.g. Purcell et al. 2001). However, in the present study, no significant difference was found in the EPR* between the two water volumes when the ratio of ctenophore WW to the volume of seawater $\leq 1: 30$. Except for the experiment performed in January $1996(\leq 1: 17)$, the ratio of WW to seawater volume was always $\leq 1: 30$. In the experiment in January 1996, an individual of $73 \mathrm{~mm}$ TL spawned, and the mean EPR* of 11 eggs $\mathrm{g} \mathrm{WW}^{-1} \mathrm{~d}^{-1}$ was almost the same as values found during November and December (cf. Table 3). Thus, we concluded that the volume of seawater did not influence the reproduction of Bolinopsis mikado.

\section{Reproductive characteristics of Bolinopsis mikado}

For Mnemiopsis leidyi, an EPR of 300-450 eggs $\mathrm{g} \mathrm{WW}^{-1}$ $\mathrm{d}^{-1}$ was reported by Kremer (1975), which corresponds to 2.7- to 4-fold of the maximum EPR* of 111 eggs g $\mathrm{WW}^{-1} \mathrm{~d}^{-1}$ for B. mikado in August 1994 (Table 3). In contrast, the egg volume of $B$. mikado calculated from the egg diameter of ca. $0.7 \mathrm{~mm}$ (Fig. 1) is 2.4- to 6.2-fold of those of $M$. leidyi and Mnemiopsis mccradyi calculated using egg diameters of $0.42 \pm 0.068 \mathrm{~mm}$ for the former (Kremer 1975) and $0.38-0.52 \mathrm{~mm}$ for the latter species (Baker \& Reeve 1974). This is consistent with the fact that the individual egg carbon weight of $0.57 \mu \mathrm{g}$ for $B$. mikado is 5.7 -fold of the $0.1 \mu \mathrm{g}$ for $M$. mccradyi estimated by Reeve et al. (1989). These results imply that there are different types of reproductive strategy among ctenophore species; small numbers of large eggs for B. mikado and vice versa for $M$. leidyi.

In the present study, the percentage of spawning individuals to the total ranged from $50 \%$ to $100 \%$, suggesting that B. mikado spawns intermittently or daily in Tokyo Bay. A similar reproductive cycle has been shown for $M$. mccradyi reared in the laboratory (Baker \& Reeve 1974). Pleurobrachia bachei has been also reported to spawn daily (Hirota 1972).

Spawning B. mikado were found even in December and January in the present study. Kasuya et al. (2000a) found small (5-15 mm TL) B. mikado in January and February in Tokyo Bay, a finding which supports the winter reproduction revealed in the present study. Since the minimum water temperature around $9^{\circ} \mathrm{C}$ in Tokyo Bay is generally recorded in January or February, B. mikado probably reproduces continuously throughout the year.

The TL of spawning B. mikado ranged from $22 \mathrm{~mm}$ to $73 \mathrm{~mm}$, indicating that $B$. mikado matures at ca. $20 \mathrm{~mm}$ TL and that $B$. mikado spawns eggs over an extensive portion of its lifespan. Kasuya et al. (2002) reared B. mikado in a laboratory using calanoid copepods Acartia spp. consisting mostly of adults as prey, and created a growth curve under a food concentration of 100 Acartia $\mathrm{L}^{-1}$, i.e. $\mathrm{TL}=$ $132.2 /\left(1+e^{5.80-0.134 t}\right)$ at $17^{\circ} \mathrm{C}$ and $\mathrm{TL}=55.3 /\left(1+e^{5.03-0.362 t}\right)$ at $24^{\circ} \mathrm{C}$. These growth curves suggest that $B$. mikado reaches a maturation size of $20 \mathrm{~mm}$ TL within $30 \mathrm{~d}$ after hatching at $17^{\circ} \mathrm{C}$, and reaches the same size within $13 \mathrm{~d}$ at $24^{\circ} \mathrm{C}$. The instantaneous growth rate of $B$. mikado increases gradually from ca. 0.4 to $0.5 \mathrm{~d}^{-1}$ with an increase in the food concentration from 10 to 100 Acartia $\mathrm{L}^{-1}$ (Kasuya et al. 2002). In addition, in Tokyo Bay, where the standing stock of Acartia-sized copepods ranges from 10 to 60 copepods $\mathrm{L}^{-1}$ (Anakubo \& Murano 1991), and the water temperature typically ranges from 9 to $28^{\circ} \mathrm{C}$ annually, the maturation time of $B$. mikado appears to be around $13 \mathrm{~d}$ in summer and more than $30 \mathrm{~d}$ in winter.

\section{Factors affecting reproduction of Bolinopsis mikado}

Because an adjusted $R^{2}$ of 0.215 was obtained from the multiple regression analysis between the EPR and ctenophore body size and water temperature, $21.5 \%$ of the EPR can be explained by these variables. The standard partial regression coefficient of 0.616 for ctenophore body size was higher than that of 0.468 for water temperature (Table 2 ), indicating that the EPR is affected more by body size than by water temperature. Nevertheless, as the range of variables was from 2.2 to $58.5 \mathrm{~g}$ for body size and from 15.1 to $25.7^{\circ} \mathrm{C}$ for water temperature, the difference of range width might influence the contribution of variables to the EPR.

Although all SR values in July 1995, including the highest SR of 3.265, were positive, those values were negative in August 1995, and after that, they were mainly negative (Fig. 2). A positive SR means that the EPR exceeded the predicted EPR, and vice versa. We determined the EPR for August 1995 using specimens collected from an area of high abundance. During mass occurrences of ctenophores, drastic declines in the abundance of natural zooplankton have been observed in the field (e.g., Deason \& Smayda 1982, Uye \& Ichino 1995, Uye \& Sano 1995). In the present study, no quantitative data were available on zooplankton abundance in the waters around the laboratory. Nevertheless, when we collected zooplankton as prey of $B$. mikado using a $0.33-\mathrm{mm}$ meshed plankton net, we had difficulty in collecting enough prey during a mass occurrence of B. mikado in August 1995. Thus, in addition to the effect of body size and water temperature, the EPR below the predicted EPR in August 1995 seems to have been affected by low food supply, and vice versa in July 1995, before the mass occurrence of $B$. mikado.

The EPR of $B$. mikado varied with $\mathrm{WW}-1.7$; the significant coefficient $b$ was 1.20 and 2.54 (Table 3), indicating that EPR depends on body size. For M. leidyi, fecundity increases linearly with ctenophore size but is variable in situ (Kremer 1975). For B. mikado, because $b$ was highly significant at $1.20(p<0.000001)$, fecundity probably increases linearly with ctenophore size, i.e. EPR* is independent of 
the body size.

The relationship between the EPR* of B. mikado and water temperature was equivalent to a $\mathrm{Q}_{10}$ value of 4.7. The relationships of the WW-specific predation and respiration rates of B. mikado to water temperature are equivalent to $\mathrm{Q}_{10}$ values of 1.8 (Kasuya et al. 1994) and 1.9 (Kasuya et al. 2000b), respectively. In addition, the relationship of the instantaneous growth rate to water temperature is equivalent to $\mathrm{Q}_{10}$ values of 5.9 and 1.4 at $17-21^{\circ} \mathrm{C}$ and at $21-27^{\circ} \mathrm{C}$ (Kasuya et al. 2002). The $\mathrm{Q}_{10}$ value for $\mathrm{EPR}^{*}$ is much higher than that of others except for the instantaneous growth rate at $17-21^{\circ} \mathrm{C}$, indicating that the investment into reproduction of the energy obtained from feeding is higher at water temperatures above $21^{\circ} \mathrm{C}$.

In Tokyo Bay, drastic population growth of B. mikado has been observed in summer and fall (Kasuya et al. 2000a). Rising water temperatures in summer and fall shorten the maturation time and lead to enhanced investment of obtained energy into reproduction. These, in turn, may lead to quick population growth and the mass occurrence of B. mikado during the summer and fall in coastal waters, with the opposite occurring in the winter and spring.

\section{Acknowledgments}

We would like to thank the staff of the Banda Marine Laboratory, Tokyo University of Fisheries (present name: Tokyo University of Marine Science and Technology), for their cooperation in collecting ctenophores. We also thank two anonymous reviewers for their helpful comments on the manuscript. This study was financially supported by a Sasakawa Scientific Research Grant from the Japan Scientific Society.

\section{References}

Anakubo T, Murano M (1991) Seasonal variation of zooplankton in Tokyo Bay. J Tokyo Univ Fish 78: 145-165. (In Japanese with English abstract)

Baker LD, Reeve MR (1974) Laboratory culture of the lobate ctenophore Mnemiopsis mccradyi with notes on feeding and fecundity. Mar Biol 26: 57-62.

Deason EE (1982) Mnemiopsis leidyi (Ctenophora) in Narragansett Bay, 1975-79: abundance, size composition and estimation of grazing. Estuar Coastal Mar Sci 15: 121-134.

Deason EE, Smayda TR (1982) Ctenophore-zooplankton-phytoplankton interactions in Narragansett Bay, Rhode Island, USA, during 1972-1977. J Plankton Res 4: 203-217.

Greve W (1970) Cultivation experiments on North Sea ctenophores. Helgoländer Wiss Meeresunters 20: 304-317.

Harbison GR, Miller RL (1986) Not all ctenophores are hermaphrodites. Studies on the systematics, distribution, sexuality and development of two species of Ocyropsis. Mar Biol 90: 413-424.

Hirota J (1972) Laboratory culture and metabolism of the plank- tonic ctenophore, Pleurobrachia bachei A. Agassiz. In: Takenouti $\mathrm{Y}$ et al. (eds.) Biological Oceanography of the Northern North Pacific Ocean. Idemitu Shoten, Tokyo, pp. 465-484.

Hirota J (1974) Quantitative natural history of Pleurobrachia bachei in La Jolla Bight. Fish Bull 72: 295-335.

Kanashiro K, Senta T (1985) Jellyfishes occurring in the coastal waters off Nagasaki peninsula, Kyushu, Japan. Bull Fac Fish Nagasaki Univ 57: 23-31. (in Japanese with English abstract)

Kasuya T, Ishimaru T, Murano M (1994) Feeding characteristics of the lobate ctenophore Bolinopsis mikado Moser. Bull Plankton Soc Jpn 41: 57-68.

Kasuya T, Ishimaru T, Murano M (2000a) Seasonal variations in abundance and size composition of the lobate ctenophore Bolinopsis mikado (Moser) in Tokyo Bay, central Japan. J Oceanogr 56: 419-427.

Kasuya T, Ishimaru T, Murano M (2000b) Metabolic characteristics of the lobate ctenophore Bolinopsis mikado (Moser). Plankton Biol Ecol 47: 114-121.

Kasuya T, Ishimaru T, Murano M (2002) Laboratory study of growth of the lobate ctenophore Bolinopsis mikado (Moser). Plankton Biol Ecol 49: 81-87.

Komai T (1915) On ctenophores of the neighbourhood of Misaki. Annot Zool Jpn 9: 451-474.

Kremer P (1975) The Ecology of the Ctenophore Mnemiopsis leidyi in Narragansett Bay. Ph. D. Thesis, University of Rhode Island, $311 \mathrm{pp}$.

Kremer P (1994) Patterns of abundance for Mnemiopsis in US coastal waters: a comparative overview. ICES J Mar Sci 51: 347-354.

Kremer P, Reeve MR (1989) Growth dynamics of a ctenophore (Mnemiopsis) in relation to variable food supply. II. Carbon budgets and growth model. J Plankton Res 11: 553-574.

Mutlu E, Bingel F, Gücü AC, Melnikov VV, Niermann U, Ostr NA, Zaika VE (1994) Distribution of the new invader Mnemiopsis sp. and the resident Aurelia aurita and Pleurobrachia pileus populations in the Black Sea in the years 1991-1993. ICES J Mar Sci 51: 407-421.

Purcell JE, Arai MN (2001) Interactions of pelagic cnidarians and ctenophores with fish: a review. Hydrobiologia 451: 27-44.

Purcell JE, Shiganova TA, Decker MB, Houde ED (2001) The ctenophore Mnemiopsis in native and exotic habitats: U.S. estuaries versus the Black Sea basin. Hydrobiologia 451: 145-176.

Reeve MR, Syms MA, Kremer P (1989) Growth dynamics of a ctenophore (Mnemiopsis) in relation to variable food supply. I. carbon biomass, feeding, egg production, growth and assimilation efficiency. J Plankton Res 11: 535-552.

Sullivan BK, Keuren DV, Clancy M (2001) Timing and size of blooms of the ctenophore Mnemiopsis leidyi in relation to temperature in Narragansett Bay, RI. Hydrobiologia 451: 113-120.

Uye S, Ichino S (1995) Seasonal variations in abundance, size composition, biomass and production rate of Oikopleura dioica (Fol) (Tunicata: Appendicularia) in a temperate eutrophic inlet. J Exp Mar Biol Ecol 189: 1-11.

Uye S, Sano K (1995) Seasonal reproductive biology of the small cyclopoid copepod Oithona davisae in a temperate eutrophic inlet. Mar Ecol Prog Ser 118: 121-128.

Zaitsev YP (1992) Recent changes in the trophic structure of the Black Sea. Fish Oceanogr 1: 180-189. 